\title{
ENTRE EVA E LILITH: DOIS CRONOTOPOS NO CAIM DE JOSÉ SARAMAGO
}

\author{
Janer Cristina Machado ${ }^{\top}$
}

\begin{abstract}
RESUMO: As personagens femininas constituem elementos decisivos na obra do romancista luso José Saramago (1922-2010). Notadamente em Caim (2009), seu derradeiro romance, despontam figuras que encarnam o feminino ativo e contestador, quais sejam as de Eva e Lilith. Partindo do conceito bakhtiniano de cronotopo, o presente estudo visa delimitar quais espaços-tempo identificam o universo actancial das referidas personagens, elegendo a dicotomia natureza/cidade como fio condutor de duas vozes que se complementam na expressão de uma polifonia feminina. Essa responde por grande parte do caráter transgressor de um protagonista que consolida sua rebeldia a partir dos encontros com mulheres fortes e questionadoras.
\end{abstract}

PALAVRAS-CHAVE: feminino; transgressão; cronotopo; José Saramago

\section{BETWEEN EVE AND LILITH: TWO CHRONOTOPES IN CAIM BY JOSÉ SARAMAGO}

\begin{abstract}
The female characters are decisive elements in the literature of Portuguese novelist José Saramago. Notably in Cain (2009), his last novel, appear figures that embody the active and argumentative feminine like Eva and Lilith. Starting from the Bakhtinian concept of chronotope, this study aims to define the space-time which identifies the actantial universe of those characters, electing the dichotomy nature / city as guide of two voices that complement each other in the expression of a female polyphony. This accounts for much of the transgressive character of a protagonist, who is consolidating his rebellion from his meeting with strong and inquisitive women.
\end{abstract}

KEYWORDS: feminine; transgression; chronotope; José Saramago

\footnotetext{
${ }^{1}$ Mestre em Letras (Estudos Literários) pela Universidade Federal de Santa Maria (UFSM)
} 


\section{Algumas palavras sobre o conceito de cronotopo}

O conceito de cronotopo compreende um dos escopos da teoria narrativa tecida pelo filósofo russo Mikhail Bakhtin (1895-1975). Constitui uma categoria conteudísticoformal na qual espaço e tempo se imbricam indissoluvelmente, com o tempo atuando enquanto quarta dimensão do espaço. Para Bakhtin,

No cronotopo artístico-literário ocorre a fusão dos indícios espaciais e temporais num todo compreensivo e concreto. Aqui o tempo condensase, comprime-se, torna-se artisticamente visível; o próprio espaço intensifica-se, penetra no movimento do tempo, do enredo e da história. Os índices do tempo transparecem no espaço, e o espaço reveste-se de sentido e é medido com o tempo. Esse cruzamento de séries e a fusão de sinais caracterizam o cronotopo artístico (BAKHTIN, 2010, p.211).

E mais: "O cronotopo como categoria conteudístico-formal determina (em medida significativa) também a imagem do indivíduo na literatura; essa imagem sempre é fundamentalmente cronotópica" (BAKHTIN, 2010, p. 212).

O mundo delimitado a partir das ações das personagens se reflete nas vozes sustentadas pelas mesmas, vozes que se confrontam e renovam de acordo com o cronotopo no qual se inserem. As vozes sociais permanecem íntegras em suas especificidades, ainda que enriquecidas pelas ideias e valores alheios, naquilo que constitui o dialogismo bakhtiniano, gerador de sentidos em constante mutação, uma vez que o homem, enquanto sujeito da vida e da literatura, é uma peça inacabada, um continuum eterno (OLIVEIRA; FREIRE, 2011).

Obra que remete diretamente ao questionamento do tempo, assestando sua trama sobre a dinâmica da estrada e dos encontros, o romance Caim, de José Saramago, comporta um grande número de cronotopos que, em seu conjunto, tipificam o escritor de Azinhaga como um autor eminentemente cronotópico (MADEIRA, 2010). São pequenos estereótipos que percorrem o texto saramaguiano, tais como o do narrador contador de histórias, o Diabo, o andarilho, entre vários outros.

Aqui destacamos a figura da mulher transgressora e questionadora, compondo uma corte de fêmeas instigantes e instigadoras, à qual Caim acrescenta um dueto de mãe e amante, natureza e cidade, que se complementa na intersecção de um protagonista ávido por justiça e pelo resgate de sua própria identidade. Tal protagonista não resiste ao fascínio dos dois cronotopos femininos que regem boa parte de seu mundo, cronotopos esses que delimitam nosso estudo a partir do presente momento, balizando uma viagem pelos meandros femininos da derradeira criação saramaguiana. 


\section{Eva ou a sedução da natureza}

A estrada de Caim não seria completa se não contasse com o tráfego da figura feminina, emblema ora velado ora explícito da sedução, que conduz à superação de limites, à reflexão e à transgressão, transformadoras de espaços-tempo e de vidas.

Tal constatação nos remete à presença das tantas mulheres fortes e decididas que povoam as páginas da obra de Saramago, as quais movem os destinos dos protagonistas masculinos, atuando como verdadeiros agentes da mudança e, nesse contexto, encarnando a pura essência da cronotopicidade bakhtiniana, cuja lei diz de renovação e confronto contínuos. Recordamos Blimunda, visionária e contestadora, em Memorial do convento (1982), e Madalena, a prostituta sábia, apaixonada e dessacralizadora de $O$ Evangelho segundo Jesus Cristo (1991), para ficarmos somente com duas das criações magistrais do autor luso e, daí, agregando o conhecimento travado em Caim com Eva e Lilith, podermos divisar um cronotopo feminino de sedução e transgressão que frequenta de forma recorrente a obra do Nobel português.

Em Caim, fica-nos claro que a primeira sedutora nesta história de deuses e de homens só pode ser a mãe, encarnada aqui na progenitora universal, aquela que gesta a continuidade da contestação na raça humana através da procriação do filho eternamente às turras com a divindade e inconformado com o mundo injusto por ela projetado. Nesse sentido, o primeiro encontro com a figura emblemática da sedutora se dá ainda quando o protagonista está no ventre materno, alimentando-se da fertilidade sombria dos recessos femininos. É daí que vai herdar seu ímpeto inquisidor e seu inconformismo, preparando-se para o enfrentamento da estrada e para os numerosos outros encontros que terá nela.

Propositora do pecado original, Eva seduz Adão para o consumo do fruto proibido e, com isso, acarreta para si mesma a punição mais pesada por parte da divindade, que não perdoa seu arbítrio decisivo em relação ao direito do homem de conhecer a verdade e todos os caminhos do conhecimento. Expulsa do Éden junto ao marido, resta-lhe a cruel maldição da potestade irritada: "Tu, eva, não só sofrerás todos os incômodos da gravidez, incluindo os enjoos, como parirás com dores, e não obstante sentirás atração pelo teu homem, e ele mandará em ti, Pobre eva, começas mal, triste destino vai ser o teu, disse eva” (SARAMAGO, 2009, p.17-18).

Enganoso, porém, é o conformismo da primeira das mulheres. É dela que parte a ideia de buscar algum alimento no feérico jardim que recém lhes foi interditado, uma vez que ela e Adão estão a morrer de fome na aridez de seu novo lar. Ao marido cético, que duvida de seu sucesso em tão ousada empresa, pois precisa pedir permissão ao querubim que guarda a entrada do paraíso, ela retorque:

Se não conseguir, não terei perdido mais que os passos para lá e para cá e as palavras que lhe disser, respondeu ela, Pois sim, mas iremos ter problemas se o querubim nos for denunciar ao senhor, Mais problemas que estes que temos agora, sem modo de ganhar a vida, sem comida para levar à boca, sem um teto seguro nem roupas dignas desse nome não vejo que problemas nos possam advir mais, o senhor já nos castigou expulsando-nos do jardim do éden, pior do que isto não imagino o que poderá ser, Sobre o que o senhor possa ou não possa não sabemos nada, Se é assim, teremos de o forçar a explicar-se, e a primeira coisa que 
deverá dizer-nos é a razão por que nos fez e com que fim, Estás louca, Melhor louca que medrosa (SARAMAGO, 2009, p. 22).

E segue contestando o marido, envolvendo-o nas malhas de uma astúcia e destemor que a ela mesma surpreendem:

Estava surpreendida consigo mesma, com a liberdade com que tinha respondido ao marido, sem temor, sem ter de escolher as palavras, dizendo simplesmente o quê, na sua opinião, o caso justificava. Era como se dentro de si habitasse uma outra mulher, com nula dependência do senhor ou de um esposo por ele designado, uma fêmea que decidira, finalmente, fazer uso total da língua e da linguagem que o dito senhor, por assim dizer, lhe havia metido pela boca abaixo (SARAMAGO, 2009, p.23).

E Eva utiliza com maestria tanto o discurso da boca como a linguagem do corpo, uma vez que esgota todas as possibilidades argumentativas junto ao anjo do Senhor na tentativa de conseguir algum alimento. De sua veemência persuasiva, constam a narração de suas agruras no deserto, mas muito mais a exibição de um sorriso e de um belo seio, capazes de tentar até mesmo a inflexibilidade celestial de um querubim, pois "Eva sorriu, pôs a mão sobre a mão do querubim e premiu-a suavemente contra o seio. $\mathrm{O}$ seu corpo estava coberto de sujidade, as unhas negras como se as tivesse usado para cavar a terra, o cabelo como um ninho de enguias entrelaçadas, mas era uma mulher, a única" (p.25).

Conquistados, por meios convencionais ou não, os favores do angélico vigilante do paraíso, Eva angaria não somente alimentos, mas também informações sobre como sobreviver na terra de cardos e espinhos à qual os condenou o Senhor, uma divindade que, contudo, ela não deixa de questionar acirradamente, ainda mais quando descobre as peculiaridades de sua criação. É assim que, chocada diante da constatação de que ela e Adão não passam de um experimento para a deidade, declara enfaticamente: "Nós não somos um assunto, somos duas pessoas que não sabem como poderão viver" (p. 27). E aí abre o questionamento dos motivos pelos quais ela e Adão foram criados, fundando, no dizer de Salma Ferraz, a filosofia. Segundo essa autora,

Eva, o Prometeu de saias hebraico [pois que de certa forma, assim como o semideus grego rouba o fogo dos deuses, Eva arrebanha a sabedoria da posse exclusiva da deidade, provando e incitando o marido a provar da árvore do conhecimento absoluto], quer saber porque afinal foram criados. Não conhece o medo, louca pode ser, medrosa nunca. A Adão talvez caiba a fundação da Teologia, ele crê e fé não exige argumentos nem explicações. Não duvida, não raciocina (FERRAZ, 2012, p. 209).

Contudo, a sobrevivência dos pais de Caim é assegurada pela acolhida cristã - termo que Saramago utiliza com requintes de ironia - proporcionada pelo anjo, acolhida da qual o Supremo Pai não se revelou capaz, e que Eva preza com "demonstração afetiva nada do agrado de seu marido" (p. 28), abraçando o querubim Azael e mesmo, mais tarde, nutrindo saudosas recordações de seu encontro. Este "segredo seu, a ninguém confiado" (p. 31) sugere todo o mistério dos ardis femininos, capazes de consorciar mulher e anjo na burla das leis do Senhor, do qual a sedutora aprende a copiar muito cedo as maquinações, ainda 
que seja em prol de sua sobrevivência e fertilizando as primeiras sementes da revolta que se fará candente na figura de seu filho.

A vida pregressa de Eva nos autoriza a aventar que é no regaço materno que a sedução é alimentada. E então acreditamos que é da mãe que Caim herda a astúcia feminina, que o faz sobreviver em meio à adversidade e à desconformidade com os desígnios divinos; dela, que uma vez soube burlar a lei para conseguir comida e sobreviver, é que ele absorve a consciência de que é preciso estar no mundo por si próprio, sem esperar nada da pouco confiável providência divina.

Nesse ponto, advogamos o pensamento das exegetas feministas da Bíblia, que atribuem um novo e decisivo papel a Eva, cuja assertividade e anseio de sabedoria opõemse à timidez, comodismo e falta de iniciativa de Adão. E aqui também não podemos deixar de nos reportar a Marie Deraismes, quando propala Eva como a verdadeira heroína bíblica, dotada da força da palavra e do exercício da inteligência, em diametral oposição à resignação e humildade de Maria, cuja postura de permanente submissão aos desejos da divindade converte-a em instrumento da Igreja e consequentemente de toda a cultura ocidental em favor da opressão feminina.

Para Deraismes, a mãe de Cristo e ideal feminino do ocidente "é a encarnação da nulidade, do apagamento; a negação de tudo quanto constitui a individualidade superior: a vontade, a liberdade, o caráter [...]. Maria é a inércia" (DERAISMES apud SCHMITTPANTEL, 2003, p. 147). E sendo a inércia, Maria é a negação do cronotopo, naquilo que ele sustenta de mobilidade transformadora, posto que a mãe de Cristo pressupõe a manutenção de um padrão feminino rígido, que se mantém inalterável ao longo dos séculos. Maria, entronizada nos altares, opõe-se à mutação renovadora da estrada, pela qual circulam cambiantes as mulheres transgressoras criadas por Saramago.

Tornando ao mundo da Eva saramaguiana, uma palpável convivência entre ela e seu filho, afora a da intimidade subentendida na certeza de que o carregou junto ao seio durante os nove meses de gestação, o narrador nos lega apenas em uma das poucas cenas de ternura inaudita na história, a do diálogo entre mãe e filho com relação ao crescimento das plantas, diálogo que, podemos naturalmente aventar, suscita na mãe risonhas esperanças de um futuro feliz e promissor para seu rebento:

Tinha quatro ou cinco anos e queria ver crescer as árvores. Então, ela [Eva], pelos vistos ainda mais imaginosa que o filho, explicou-lhe que as árvores são muito tímidas, só crescem quando não estamos a olhar para elas, É que lhes dá vergonha, disse-lhe um dia. Por alguns instantes caim permaneceu calado, a pensar, mas logo respondeu, Então não olhes, mãe, de mim não têm vergonha, estão habituadas. Prevendo já o que viria depois, a mãe apartou o olhar e imediatamente a voz do filho soou triunfal, Agora mesmo cresceu, agora mesmo cresceu, eu bem te tinha dito que não olhasse (SARAMAGO, 2009, p. 38).

Daí podemos deslindar outra Eva, que além de sedutora e contestadora, também é geradora e nutriz: ela anseia a vida e a felicidade para seu filho, compartilha de seus ingênuos sonhos da infância, embora se veja, mais uma vez, traída pela falta de misericórdia da divindade. Deus lhe rouba a harmoniosa convivência com o filho, condenando-o ao exílio e assim interditando-lhe tanto o contato com a família como o ansiado futuro de 
cultivador, semeador de alimento e vida. Conforma-se aí a dupla separação, que segrega o filho não apenas daquela que o gerou em seu ventre, mas também das lides da terra, ela que é a maior e mais primordial das mães.

Para Caim, o encontro mágico no horto de sua infância perde-se para sempre uma vez que ingressa na espiral das eras, diluindo-se o espaço-tempo da felicidade e da inocência na constatação de que o mundo e seu deus são injustos, tão injustos quanto a perda de sua família, quiçá mais ainda da mãe, de quem herdou o espírito inquisitivo e a rebeldia. Uma vez abandonada a casa da infância, relega-se ao passado o cronotopo da mãe, cuja sedução da vida descompromissada, integrada à natureza e alheia à maldade do mundo, não pode mais ser usufruída, mediante a constatação de que a divindade a tudo polui com sua sede de poder e arbitrariedades.

Deixando a mãe, cumpre que o protagonista se aventure por outros caminhos sedutores, quais sejam os da mulher que se faz amante, e transpondo assim o espaço-tempo da natureza para o espaço-tempo da cidade - cidade fêmea, regaço que convida não mais ao simples e ingênuo repouso, mas sim ao êxtase da carne com toda a violência de suas ações.

\section{Lilith ou a provocação da cidade}

Conta a Bíblia que Caim, depois de assassinar Abel, partiu para um país ao leste do Éden, conhecido como Terra de Nod. Ali teve um filho chamado Enoch e construiu uma cidade à qual deu o mesmo nome de seu primeiro rebento. Porém, sobre a mulher com quem gerou esse filho, o Livro Sagrado silencia, cabendo aos caminhos da ficção explorar seu segredo.

Onde a Bíblia se cala e a ficção entoa a palavra, encontramos o protagonista de Saramago, que também se aventura pelas plagas de Nod e participa da edificação de uma urbe, ainda que sua empreitada tome rumos diferentes, rechaçando o "fincar raízes" que conforma a constituição de uma família aos moldes patriarcais, como relata a Sagrada Escritura. Sendo Nod "terra da fuga" ou "terra dos errantes", caracteriza assim um território movediço, bastante improvável para a construção de uma cidade com todas as suas implicações de permanência. Desse mote se serve o escritor luso para alavancar os destinos de seu protagonista, o qual tem em Nod a porta de entrada para suas deambulações pelos tempos passados e futuros, comportando o ingresso no universo dos seres sem tempo ou de todos os tempos. É nesse espaço da errância e do nada, paradoxalmente pleno de possibilidades, que Caim encontra uma urbe incipiente, arremedo de cidade que se nos desenha com claros contornos:

Aí está a praça. Em verdade, ter chamado a isto uma cidade foi um exagero. Umas quantas casas térreas mal alinhadas, umas quantas crianças brincando não se sabe a quê, uns adultos que se movem como sonâmbulos, uns burros que parecem ir aonde querem e não aonde os conduzem, qualquer cidade que se preze desse nome nunca se reconhecerá na cena primitiva que temos diante dos olhos (SARAMAGO, 2009, p. 47). 
A esse locus de indefinição, ao qual faltam os confortos e conveniências da modernidade, no entanto, o narrador já anuncia os benefícios do progresso, que aponta ser tão inexorável como a vida e a morte. Do engrandecimento dessa cidadela perdida na aridez errante, deve participar Caim, empregando sua força na pisa do barro do qual se formarão os tijolos de adobe, elemento fundamental para a edificação dos palácios e templos da futura metrópole. Eis a descrição desse labor mecânico e repetitivo, no qual se gesta a grandeza de futuras civilizações:

Aqui está a pisa do barro. Um grupo de homens com a túnica arregaçada com um nó acima do joelho dava voltas na grossa camada de uma mistura de barro, palha e areia, calçando-a com determinação de modo a tornar a massa tão homogênea quanto fosse possível na falta de meios mecânicos. Não era um trabalho que exigisse muita ciência, apenas boas e sólidas pernas (SARAMAGO, 2009, p.49).

Se a mecânica pisa do barro é serviço para homens, quem dita as regras na cidade em construção é uma mulher: "E o senhor daqui, é quem [pergunta o recém-chegado Caim], O senhor é senhora e o seu nome é lilith, Não tem marido, perguntou caim, Creio ter ouvido dizer que se chama noah, mas ela é quem governa o rebanho, disse o olheiro" ( p. 49).

E mais:

Diz-se que é bruxa, capaz de endoidecer um homem com os seus feitiços, Que feitiços, perguntou caim, Não sei nem quero saber, não sou curioso, a mim basta-me ter visto por aí dois ou três homens que tiveram comércio carnal com ela, E quê, Uns infelizes que davam lástima, espectros, sombras do que haviam sido, Deves estar louco se imaginas um pisador de barro a dormir com a rainha da cidade, Queres dizer a dona, Rainha ou dona tanto faz, Vê-se que não conheces as mulheres, são capazes de tudo, do melhor e do pior se lhes dá para isso, são muito senhoras de desprezar uma coroa em troca de ir ao rio lavar a túnica do amante ou atropelarem tudo e todos para chegarem a sentar-se num trono (SARAMAGO, 2009, p. 51).

Senhora absoluta de sua urbe, Lilith encarna a autoridade inusitada, mas ao mesmo tempo temida e respeitada em um mundo primitivo e regrado pelo poder masculino. Ela não se furta ao contato com o povo e à supervisão direta de seus empreendimentos, tanto quanto ao livre usufruto de seu corpo, que não restringe ao marido, nem aos recessos do palácio senhorial.

Decidida a tomar Caim como amante, ela ordena que ele seja transferido da pisa de barro para o serviço interno do palácio onde vive. Ali, o primeiro fratricida passa por uma iniciação sexual nas mãos das escravas da senhora e espera durante longo tempo até que a mesma o considere apto a se tornar seu parceiro de cama. E, finalmente, ao recebê-lo pela primeira vez na casa senhorial, a soberana das terras de Nod tece cuidadosamente seu ritual de sedução, trajando "um vestido que exibia com mínimo recato um decote que deixava a ver a primeira curva dos seios e adivinhar o resto" (p. 56). É assim, devidamente caracterizada como uma mulher mundana e adepta de refinadas práticas citadinas, que ela 
reafirma seu poder sobre a urbe, deixando claro a Caim que é a única e verdadeira voz de comando naquelas plagas:

Estarás sempre nesta antecâmara, de dia e de noite, tens ali o teu catre e um banco para sentares, serás, até que eu mude de ideias, o meu porteiro, impedirás a entrada de qualquer pessoa, seja quem for, no meu quarto, salvo as escravas que o vêm limpar e arrumar, Seja quem for, senhora, perguntou caim sem aparente intenção, Vejo que és ágil de cabeça, se estás a pensar no meu marido, sim, também esse não está autorizado a entrar, mas ele já o sabe, não tens que lho dizer, E se mesmo assim quiser alguma vez forçar a entrada, És um homem robusto, saberás como impedi-lo, Não posso enfrentar pela força quem, sendo senhor da cidade, é senhor da minha vida, Podes se eu to ordenar (SARAMAGO, 2009, p. 56-57).

Essa mulher, que "quando finalmente abrir as pernas para se deixar penetrar, não estará a entregar-se, mas sim a tratar de devorar o homem a quem disse, Entra" (p. 59), encarna à perfeição a imagem da cidade transgressora: rebelde contra a autoridade oficialmente reconhecida, que é sempre casta e masculina, ela exalta a liberdade dos corpos e das mentes, propalando uma ambiência subversora do papel dos gêneros e estamentos sociais, somente concebível na turbulência fecunda e cambiante dos espaços urbanos. Nesse sentido, não é aleatório que o mito de Lilith tenha surgido justamente na região onde se desenvolveram as primeiras cidades da História, cotejando o vicejar da vida urbana com a eterna rebeldia e desconfiança diante do sexo feminino.

Sobre a Lilith lendária, contam-se muitas versões, advindas das mitologias suméria e judaica: ora é a primeira mulher de Adão, expulsa do paraíso pela sua insubmissão à autoridade masculina; ora é a misteriosa mulher com quem Caim procriou sua posteridade quando exilado ao leste do Éden (opção que aqui estudamos na brilhante releitura saramaguiana); ora ainda é um demônio sexual que aterroriza as noites de homens e mulheres, devora crianças e parteja íncubos e súcubos (HURWITZ, 2006).

Senhora de sua urbe, a Lilith de Saramago se reporta às mulheres fortes do matriarcado, tipo de civilização em que a figura feminina sobressai enquanto conhecedora do mistério da vida e acumuladora de experiência. Podemos mesmo afirmar que sua metrópole perdida na Terra de Nod preserva algo desse modus vivendi que foi dominante no Paleolítico e no Neolítico, marcado pela proeminência do papel feminino e pelo culto da paz em oposição ao afã guerreiro masculino. A divindade principal no panteão dessa sociedade é a Grande Mãe, deusa poderosa na mitologia e religião do antigo Oriente Próximo, cujos atributos Campbell oportunamente descreve:

A mulher dá a luz, assim como da terra se originam as plantas. Assim, a magia da mãe e a magia da terra são a mesma coisa. Relacionam-se. A personificação da energia que dá origem às formas e as alimenta é essencialmente feminina. A Deusa é a figura mítica dominante no mundo agrário da antiga Mesopotâmia, do Egito e dos primitivos sistemas de cultura do plantio [...]. Quando você tem uma Deusa como criador, o próprio corpo dela é o universo. Ela se identifica com o universo (CAMPBELL, 2009, p. 177). 
Nesse sentido, a amante de Caim se faz universo em conjunto com a polis que patrocina. Ela referenda em seu comportamento a figura da Deusa, revela-se carnal e terrena, opondo-se à divindade autocrática configurada como espiritual e celestial. Soberana de seu povo, recusa-se a ser terra pisada pelo orgulho masculino de homens e deuses, para converter-se em terra fértil e opulenta, geradora de vida que dá continuidade à lenda e à crônica de sua cidade. Insertos nesse viés, observamos, contudo, que nas histórias contadas, quer sejam por um demônio ou por uma deusa, a ênfase recai sempre na representação da sexualidade em seu estado mais brutal e primitivo, na fêmea insaciável que "devora homens com seu órgão sexual e desconhece o poder e a culpa" (FERRAZ, 2012, p. 215).

No romance de Saramago, a devoradora de homens tende para o lado da deusa no momento em que sustenta um propósito definido, o qual alude diretamente à sobrevivência de seus domínios. Incapaz de gerar um filho do marido, Lilith procura em outros parceiros sexuais a concepção de um rebento que herde a cidade em construção, um senhor que dará nome e continuidade à desolada Terra de Nod, agora convertida em floresta de adobe. Eis que explicado está o comportamento complacente de Noah, o esposo passivo diante das constantes infidelidades da rainha do lugar:

Marido consentidor como os que mais o têm sido, noah, em todo o tempo, como é costume dizer-se de vida em comum, havia sido incapaz de fazer um filho à mulher e fora justamente a consciência desse contínuo desaire, e talvez também a esperança de que lilith acabasse por engravidar de um amante ocasional e lhe desse finalmente um filho a quem pudesse chamar herdeiro, que o havia levado a adotar, quase sem perceber, essa atitude de condescendência conjugal que, com o tempo, viria a tornar-se em cômoda maneira de viver, só perturbada pelas raríssimas vezes em que lilith, movida pelo que imaginamos ser a tão falada compaixão feminina, decidia ir ao quarto do marido para um fugaz e insatisfatório contato que a nenhum dos dois comprometia, nem a ele para exigir mais do que lhe era dado, nem a ela para the reconhecer esse direito (SARAMAGO, 2009, p.61).

É, pois, no sentido da preservação da urbe que se justifica a licenciosidade de Lilith e a conivência de Noah. E a senhora da cidade ressalta ainda: "Não sou mulher para remorsos, isso é coisa para fracos, para débeis, eu sou lilith" (p. 69), coroando a necessidade de um pulso firme e de atitudes arrojadas quando se visa à continuidade de sua criação maior, o espaço urbano.

Como já vimos, o encontro com Eva, a mãe, representa a sedução da natureza, a vigência de um espaço-tempo permeado pela inocência e pela comunhão com as plantas e, por extensão, com as sementes de todos os planos de vida, ainda que essas remetam infalivelmente à futura contestação e rebeldia. Mas é na sedução da cidade que essas sementes brotam e amadurecem, na figura de Lilith, a amante, que Caim ingressa definitivamente no espaço-tempo da transgressão, acolhendo o prazer e a dor de bastar-se a si mesmo e de interrogar-se e interrogar o mundo constantemente.

A passagem do ventre materno para o ventre sexual ratifica a imersão em um cronotopo essencialmente urbano e coletivo, no qual lugares e momentos já não podem ser 
medidos ou percebidos através da contínua e infalível mutação dos ciclos vegetais e das estações, confinando-se ao homem a sua condução e controle, por meio de relógios e calendários. E, se as ações humanas passam a reger, de certa forma, a conformação das eras e dos sítios, faz-se inevitável a violação da paz e da igualdade social, uma violação que assume cada vez mais as feições de uma divindade que alimenta ambições guerreiras e que catapultou a desigualdade no exato instante em que preferiu Abel a Caim.

Contudo, a marca da sedução imprime-se aos dois cronotopos - o da mãe/natureza e o da amante/cidade - através da figura feminina, denegrida na Bíblia e na lenda judaica, mas exaltada na leitura saramaguiana, que devolve à Eva e à Lilith seu status de motus transformadores, na medida em que não se calam diante de suas dúvidas e de seus desejos. Como ressalta Sicuteri, "Lilith pede para ser considerada igual, Eva pensa que não há morte ao assumir a sabedoria proibida. Lilith desobedece à supremacia de Adão, Eva desobedece à proibição. Ambas assumem um risco mediante um ato" (SICUTERI, 1985, p. 38). Aqui percebemos que o pensamento de Saramago se aproxima do de Sicuteri, quando o primeiro atribui à sua Eva a primazia na contestação e reflexão sobre os desígnios divinos, e faz a sua Lilith prevalecer sobre Noah como senhora de seu corpo e de sua urbe.

Reportando-nos às concepções de Gilbert Durand (2002), contrapomos os dois cronotopos femininos aqui deslindados, unidos sob a égide da fêmea sedutora e transgressora, por si só um estereótipo (MADEIRA, 2010) no texto saramaguiano, ao cronotopo da divindade, naquilo que podemos descrever como um embate entre os regimes uraniano e telúrico da existência - oposição entre a rigidez do patriarcado celeste, diurno e repressor, e a maleabilidade do matriarcado terreno, noturno e libertário.

No entanto, o lugar e o momento da sedução, a noite da natureza e da cidade, ventre de Eva e ventre de Lilith, preservam ao lado da rebeldia e da liberdade o gérmen de todos os temores de dissolução e de ambivalência entre atração e repulsa. É assim que Eva esconde seus segredos em relação ao querubim guardião do Éden e Lilith incita à tortura e ao assassinato dos agressores de Caim.

Nas palavras de Durand, "a beleza acompanha a deusa ctônia e em torno da morte e da queda do destino temporal formou-se pouco a pouco uma constelação feminina e em seguida sexual e erótica" (DURAND, 2002, p. 195). E o erotismo que anda de braços com a morte é algo que Saramago não deixa passar incólume quando descreve os amores de Caim com a senhora da urbe e o efeito que provocam no marido traído:

\footnotetext{
Lilith era insaciável, as forças de caim pareciam inesgotáveis, insignificante, quase nulo, o intervalo entre duas ereções e respectivas ejaculações, bem poderia dizer-se que estavam, um e outro, no paraíso do Alá que há-de-ser [...]. Neste momento, apesar da porta fechada, a veemência das expansões eróticas dos dois parceiros atingia o pobre homem como sucessivas bofetadas, dando lugar nele ao nascimento súbito de um sentimento que não havia experimentado antes, um ódio desmedido ao cavaleiro que montava a égua lilith e a fazia relinchar como nunca (SARAMAGO, 2009, p. 61-62).
}

Assim, o espaço-tempo telúrico, ainda que libertador em suas expressões de natureza e cidade, também carrega consigo as potencialidades destruidoras, a obscuridade e perigos de um devir regido pela inconstância feminina, cuja qualidade sedutora, encarnada 
na fluidez da noite, eufemiza-se nas manifestações da sexualidade, mas não oculta de todo a agonia e a morte (DURAND, 2002). Na verdade, essas últimas estão mais presentes do que nunca na cópula quase que animalizada, no corpo mecanizado que atua como autômato de prazer simultaneamente à dor e traição de outro corpo.

Se Baltazar e Blimunda, Raimundo e Sara, Jesus e Madalena, para citar apenas três dos apaixonados casais da obra saramaguiana, se encontram na cumplicidade carnal de sua paixão, nela se iluminando e transcendendo a pura materialidade, a relação entre Caim e Lilith, ainda que indubitavelmente mais clamorosa no que tange à expressão da sexualidade, admite a ascensão de uma forma diversa: no amplexo sinistramente amoroso de Lilith, Caim se descobre, antiteticamente, como o elemento feminino do casal, soterrado na polifonia agressiva da senhora da Terra de Nod: "Ninguém é uma só pessoa, tu, caim, és também abel, E tu, eu sou todas as mulheres, todos os nomes delas são meus, disse lilith" (SARAMAGO, 2009, p. 126).

Do aprendizado da submissão ao corpo e à paixão, Caim extrai a percepção feminina da existência, coleta a energia para seguir seu périplo mais sábio e reflexivo, pois que a experiência com Lilith autoriza-o a ser um pouco mais todos os homens, assim como provou nela de todas as mulheres.

\section{BIBLIOGRAFIA}

BAKHTIN, M. Questões de literatura e estética: a teoria do romance. São Paulo: HUCITEC, 2010.

CAMPBELL, J. O poder do mito. São Paulo: Palas Athena, 2009.

DURAND, G. As estruturas antropológicas do imaginário: introdução à arquetipologia geral. 3. ed. São Paulo: Martins Fontes, 2002.

FERRAZ, S. As faces de Deus na obra de um ateu: José Saramago. 2.ed. Blumenau: EDIFURB, 2012.

HURWITZ, S. Lilith, a primeira Eva: aspectos históricos e psicológicos do lado sombrio feminino. São Paulo: Fonte Editorial, 2006.

MADEIRA, W. Cronotopo: figuração da forma ficcional de Saramago. Bakbtiniana, São Paulo, v.1, n.4, jul./dez., 2010. Disponível em: http://www.revistaspucsp.br/index.php/bakhtiniana/article/view/4299 Acesso em: 02 fev. 2010.

OLIVEIRA, M. E.; FREIRE, M. O cronotopo narrativo: uma análise do romance Dôra, Doralina. In: Anais do SILEL. Uberlândia, EDUFU, 2011, v.2, n.2.

SARAMAGO, J. Caim. São Paulo: Companhia das Letras, 2009.

SICUTERI, R. Lilith: a lua negra. Rio de Janeiro: Paz e Terra, 1985.

SCHMITT-PANTEL, P. A “criação da mulher": um ardil para a história das mulheres. In: MATOS, M.I.; SOIHET, R. (Org.). O corpo feminino em debate. São Paulo: Editora da UNESP, 2003. 